\title{
Article
}

\section{The Impact of Having a Holiday or Work in Fiji on Perceived Immune Fitness}

\author{
Joris C. Verster ${ }^{1,2, * \mathbb{D}}$, Lizanne Arnoldy ${ }^{1,2}$, Aurora J.A.E. van de Loo ${ }^{1} \mathbb{D}$, Aletta D. Kraneveld ${ }^{1}$, \\ Johan Garssen 1,3 ${ }^{(D)}$ and Andrew Scholey 2 (D) \\ 1 Utrecht Institute for Pharmaceutical Sciences (UIPS), Division of Pharmacology, Utrecht University, \\ 3584 CG Utrecht, The Netherlands; larnoldy@swin.edu.au (L.A.); a.j.a.e.vandeloo@uu.nl (A.J.A.E.v.d.L.); \\ a.d.kraneveld@uu.nl (A.D.K.); j.garssen@uu.nl (J.G.) \\ 2 Centre for Human Psychopharmacology, Swinburne University of Technology, \\ Melbourne, VIC 3122, Australia; Andrew@scholeylab.com \\ 3 Immunology Platform for Specialized Nutrition, Danone Nutricia Research, \\ 3584 CT Utrecht, The Netherlands \\ * Correspondence: j.c.verster@uu.nl; Tel.: +31-30-253-6909
}

Citation: Verster, J.C.; Arnoldy, L.; van de Loo, A.J.A.E.; Kraneveld, A.D.; Garssen, J.; Scholey, A. The Impact of Having a Holiday or Work in Fiji on Perceived Immune Fitness. Tour. Hosp. 2021, 2, 95-112. https:// doi.org/10.3390/tourhosp2010006

Academic Editor: Brian Garrod Received: 30 December 2020

Accepted: 4 February 2021

Published: 8 February 2021

Publisher's Note: MDPI stays neutral with regard to jurisdictional claims in published maps and institutional affiliations.

Copyright: (c) 2021 by the authors. Licensee MDPI, Basel, Switzerland. This article is an open access article distributed under the terms and conditions of the Creative Commons Attribution (CC BY) license (https:// creativecommons.org/licenses/by/ $4.0 /)$.

\begin{abstract}
The Western $24 \mathrm{~h}$ society poses great psychological and physical demands on people, which may result in complaints such as stress or being overworked, and reduced immune fitness. Having a holiday may be a good way to reduce work-related stress and reduced mood and improve perceived immune fitness. Therefore, the aim of the current study was to assess the impact of having a holiday or work on perceived immune fitness and mood. A survey was held among $N=246$ young adults who were on holiday in Fiji, and $\mathrm{N}=87$ subjects who were in Fiji for work. The sample comprised both students and individuals with a job at home. Past year immune status was assessed with the Immune Status Questionnaire (ISQ). Current perceived immune functioning and mood were rated from 0 (very poor) to 10 (excellent). Assessments were made for two occasions: (1) the current situation (in Fiji), and (2) at home (before traveling). Compared to being at home, both students and working individuals on holiday in Fiji reported significantly improved immune fitness and significantly improved mood. For example, both groups reported reduction of stress of about $60 \%$ while in Fiji. In students who came to Fiji for work or spending a holiday, improvements in perceived immune fitness were more pronounced than in working people coming on holiday in Fiji. In contrast, working people on holiday reported greater improvements in mood compared to students. The magnitude of improvements were significantly greater among women than men. In conclusion, the data suggest that both having a holiday or working in Fiji is associated with significant improvements of mood, which were themselves associated with improved immune fitness. The findings are of importance for the tourism industry as they demonstrate that, in addition to leisure (or being active) as a purpose for having a holiday, the observed mental health benefits and improved perceived immune fitness provide an additional motive to have a holiday.
\end{abstract}

Keywords: immune functioning; mood; stress; holiday; vacation; work; Fiji

\section{Introduction}

The Western $24 \mathrm{~h}$ society poses great psychological and physical demands on people, which may result in complaints such as stress, being overworked, and sleep disturbances. This can ultimately lead to reduced immune fitness and associated illnesses. Indeed, a growing body of scientific literature reports on occupational stress resulting in absenteeism and presenteeism, or even burnout [1-3]. In this article, we investigate to what extent a vacation/holiday, i.e., an extended period of leisure and recreation, spent away from home or in travelling, may have a positive impact on recovering from the demands of 24 h society.

Leiter and Maslach conducted several studies on the causes of occupational stress and found that environmental factors such as job characteristics, workload, control and reward, 
and support from colleagues can all act as determinants of occupational stress [4]. The European framework for psychosocial risk management (PRIMA-EF) identified relevant work-related psychosocial hazards, including a lack of variety in work content, work overload, irregular work schedules, low participation in decision making, poor communication in the organization, career stagnation and job uncertainty, and poor working conditions [5]. It has been estimated that the forthcoming stress is the most commonly reported job-related illness, affecting over 40 million individuals across Europe [6]. It is therefore important to address these determinants in order to prevent job stress, and investigate ways to recover from job stress, such as having a vacation.

In addition, the immune system may play a relevant role in the development and recovery from occupational stress. Immune resilience is essential to how the body recognizes and defends itself against exposure to external agents, including bacteria, viruses, and other agents (e.g., alcohol and drugs). Exposure to psychological factors such as work-related stress can also negatively impact immune resilience [7]. One of the ways to "reset" somatic and psychological processes from the effects of occupational stress may be to have a break, for example by taking a holiday. Not surprisingly, the limited body of research on health effects of holidays reports significant positive health effects and a reduction in stress [8-12].

Immune fitness has been defined as a state where an individual's immune system is resilient, having an inbuilt capacity to adapt to challenges by establishing, maintaining, and regulating an appropriate immune response in order to promote health and prevent and resolve disease, improving quality of life. Studies specifically addressing holiday effects on immune fitness are scarce and have provided inconsistent results [9,11,13]. Koh et al. [7] showed that, compared with a stress-free control period, Korean students experienced high stress levels during the exam period. Their proinflammatory cytokine IL-6 concentration in blood was significantly reduced, while anti-inflammatory cytokine IL-10 levels were significantly elevated during the exam period. During a subsequent holiday, concentrations of the proinflammatory cytokines IL- 6 and TNF- $\alpha$ significantly increased. Interestingly, the changes in self-reported stress and anxiety levels did not significantly correlate with any changes in blood cytokine concentrations. Thus, having a holiday may affect immune functioning independently of self-reported stress.

Epel et al. [11] examined holiday effects in a working population. They showed that a 6-day holiday to a Spa Resort was associated with significant positive effects on stress and immune functioning. Analysis of blood sample obtained before and after the vacation revealed significant gene expression changes that were characterized by improved regulation of stress response, immune function, and amyloid beta (A $\beta$ ) metabolism. Having a holiday was accompanied by a significant suppression of pathways related to defense response, wound healing, and inflammation. This was also evident from a significant increase in blood tumor necrosis factor alpha (TNF- $\alpha$ ) levels observed after the vacation. The assessments were accompanied by significantly improved subjective ratings of wellbeing 1 and 10 months after the holiday.

Ceballos et al. [13] examined students on a spring-break holiday and assessed immune functioning before and after the holiday. For a substantial subgroup of students, spring break is characterized by excessive alcohol consumption and drug use, sleep deprivation, and untamed party behavior. Saliva sample assessments revealed significantly reduced immune responsiveness (decreased IgA:albumin levels) as a result of a week of heavy alcohol consumption and partying. Interestingly, the drinking behavior and immune responses varied between students, depending on their cortisol response. Students who experienced a cortisol increase after the spring-break holiday had less responsive immune systems compared to students whose cortisol levels were unaltered (i.e., the latter group showed no decrease in IgA:albumin levels). Blunted cortisol response and decreased immune functioning was associated with a twofold increase in alcohol consumption during the holiday. This study illustrates that, in some populations, holidays may also be characterized predominantly by behaviors such as alcohol and drug use [14] that may compromise immune fitness. Other research suggests that holidays can also be 
characterized by various other causes of distress-for example when experiencing travelrelated health issues [8], violence, accidents, or injury [15,16].

In the three studies that demonstrated immunological changes associated with having a holiday, the nature of these changes, i.e., immune-stimulation or immune-suppression, depends on the behaviors and lifestyle during the holiday (e.g., relaxation versus party, alcohol use). In the reviewed studies, perceived immune fitness was not assessed. Therefore, the current study aimed to further investigate the impact of having a holiday on self-reported mood and immune fitness. As logistics and budget did not allow biomarker assessment of immune fitness, a survey was conducted to assess perceived immune fitness. To this extent, Fiji, a beach holiday destination, was chosen to conduct the study, as this was hypothesized as a suitable environment to recover from work or study at home. It was hypothesized that both having a break from work (i.e., being in Fiji for holiday) and an environmental change (i.e., being in Fiji to work) have a positive effect on perceived mood and immune fitness. It was further hypothesized that with increased duration of being in Fiji, the reported improvements will be more prominent.

\section{Materials and Methods}

In August 2018, a survey was conducted among young adults in Fiji. Fiji is a major holiday destination that consists of 333 islands, and is located in the heart of the South Pacific (See Figure 1).

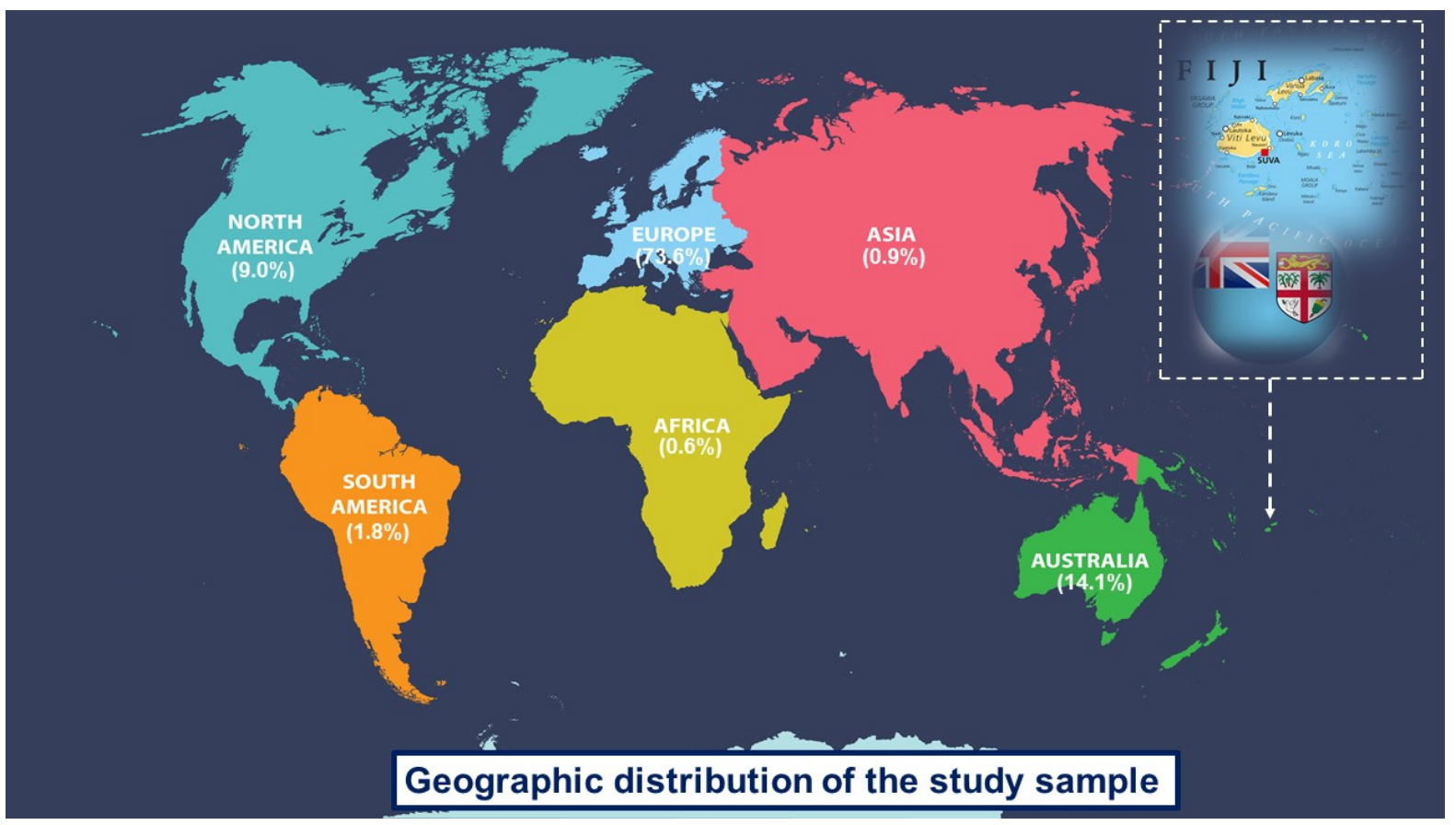

Figure 1. Geographical distribution of the study sample. Used and adapted with permission from www.depositphotos.com (accessed on 30 December 2020).

It was aimed to include international young adults that came to Fiji either for work or holiday. Hence, native Fijians were excluded from participation. Both men and women were included, within the age range of 18 to 35 years old. Young adults we chosen as this sample allows a direct comparison of workers and students within the same age range. Young adults were approached at Wailoaloa beach, and asked to complete a survey. Waioloaloa beach is a $3 \mathrm{~km}$ stretch of beach, close to Nadi and the International airport. Wailoaloa has a beach, bars, and budget accommodations. At these venues, participants for the survey were recruited. These venues predominantly attract relatively young international travelers. In addition to holidaymakers, young adults also travel to 
Fiji for work, mostly in the tourist industry. These young adults also regularly visit the beachfront bars at Wailoaloa beach.

Subjects who were willing to participate and understood English language completed the survey on location. The investigator was present to explain possible ambiguities with regards to language comprehension of the international audience of participants (See Figure 1). The study was conducted by Utrecht University and the Ethics Committee of the Faculty of Social and Behavioral Sciences of Utrecht University granted ethical approval (approval code FETC17-061), and informed consent was obtained from all subjects. The survey was anonymous and subjects did not receive an incentive for completing the survey. $\mathrm{N}=333$ subjects completed the survey. Subjects originated from 29 different countries, with most of them coming from Europe (see Figure 1 for a geographical distribution of the study sample).

The survey gathered information on demographics such as sex, age, country of citizenship, occupation, height and weight, and ethnicity. Information on how many subjects were abroad (traveling) with respect to their country of residence, and how long they had been in Fiji, was also recorded.

\subsection{Perceived Immune Fitness}

To assess past year's immune status (i.e., before traveling to Fiji), the Immune Status Questionnaire (ISQ) was completed [17]. The ISQ consists of 7 items, including "common cold," "diarrhea," "sudden high fever," "headache," "muscle and joint pain," "skin problems" (e.g., acne and eczema), and "coughing." The items are scored on a 5-point Likert scale stating how often the items experienced these complaints during the past year, including "never," "sometimes," "regularly," "often," and "(almost) always." The overall ISQ score ranges from 0 (poor) to 10 (excellent), with higher scores indicating a better immune fitness. The ISQ has a Cronbach's alpha of 0.63 and a test-retest reliability of 0.80 [17].

Current immune fitness (in Fiji) was assessed using the 1-item perceived immune functioning scale $[18,19]$. The scores on this scale also range from 0 (poor) to 10 (excellent), with higher scores indicating a better perceived immune fitness.

\subsection{Mood}

A short scale was developed to assess mood. The six 1-item scales reflected some of the subscales of the short version of the Profiles of Mood States (POMS) [20], and included "stress," "anxiety," "depression," "being active," "fatigue," and "anger." These items were scored on a scale ranging from 0 (absent) to 10 (extreme). The assessments were conducted for two occasions: (1) being at home (before traveling), and (2) the current situation (while being in Fiji).

\subsection{Alcohol Use and Sleep}

For the three days preceding completion of the survey, subjects were asked to report the number of alcoholic drinks they consumed on each day. The survey contained guidance about standard drinking sizes, and how to convert for example bottles of wine into standardized alcohol units, to obtain a more reliable measure of alcohol intake in Fiji that accounts for day-to-day variations. The average alcohol intake of the three days was computed. Weekly alcohol consumption at home (before traveling) was also recorded.

Subjects also reported the number of hours they slept the preceding three days and they rated the corresponding sleep quality on a scale ranging from 0 (poor) to 10 (excellent) [18]. For these assessments, the 3-day average was completed to represent sleep outcomes in Fiji (total sleep time and sleep quality).

\subsection{Statistical Analysis}

Statistical analyses were conducted with SPSS (IBM Corp. Released 2013. IBM SPSS Statistics for Windows, Version 25.0. IBM Corp., Armonk, NY, USA). 
Subjects were allocated to one of four groups: (1) work at home, work in Fiji, (2) work at home, on holiday in Fiji, (3) student at home, work in Fiji, and (4) student at home, holiday in Fiji.

First, demographic data for the sample and sub groups was investigated. Mean and standard deviation (SD) were computed for each variable. Comparisons were made between (1) being at home (before traveling), and (2) the current situation (while being on holiday in Fiji). Depending on the distribution of the data, independent t-tests (normal distribution) or Independent Samples Mann-Whitney U tests (nonparametric distribution) were applied to compare assessments between groups.

Second, to compare assessments within groups, paired t-tests (normal distribution) or Related-Samples Wilcoxon Signed Rank tests (nonparametric distribution) were used to compare assessments at home versus Fiji. These were conducted for the overall sample and the sub groups. Spearman's rho correlations were computed to investigate the relationship between immune fitness, mood outcomes, and neuroticism. For these correlations, difference scores were used ( $\Delta=$ "in Fiji" minus "at home").

Third, the data was interrogated for potential sex differences. Depending on the distribution of the data, independent t-tests (normal distribution) or Independent Samples Mann-Whitney U test (nonparametric distribution) were applied to compare groups.

Fourth, it was investigated whether levels of mood and immune fitness at home had an impact on the improvements observed in Fiji. Spearman's rho correlations between difference scores $(\Delta=$ "in Fiji" minus "at home") were calculated for immune fitness and mood ratings. These were correlated with the same ratings made at home.

Fifth, using similar analysis, the impact of possible confounding factors such as alcohol use, sleep and days in Fiji were examined. Results were considered statistically significant if $p<0.05$.

\section{Results}

Of the sample $(\mathrm{N}=333), 44.4 \%$ reported being students at home, $6.0 \%$ reported being unemployed, and $49.6 \%$ reported having a job at home. The majority of subjects were in Fiji for holiday $(\mathrm{N}=246,73.9 \%)$, while about a quarter of the sample was in Fiji to work ( $\mathrm{N}=87,26.1 \%$ ) (See Figure 2).

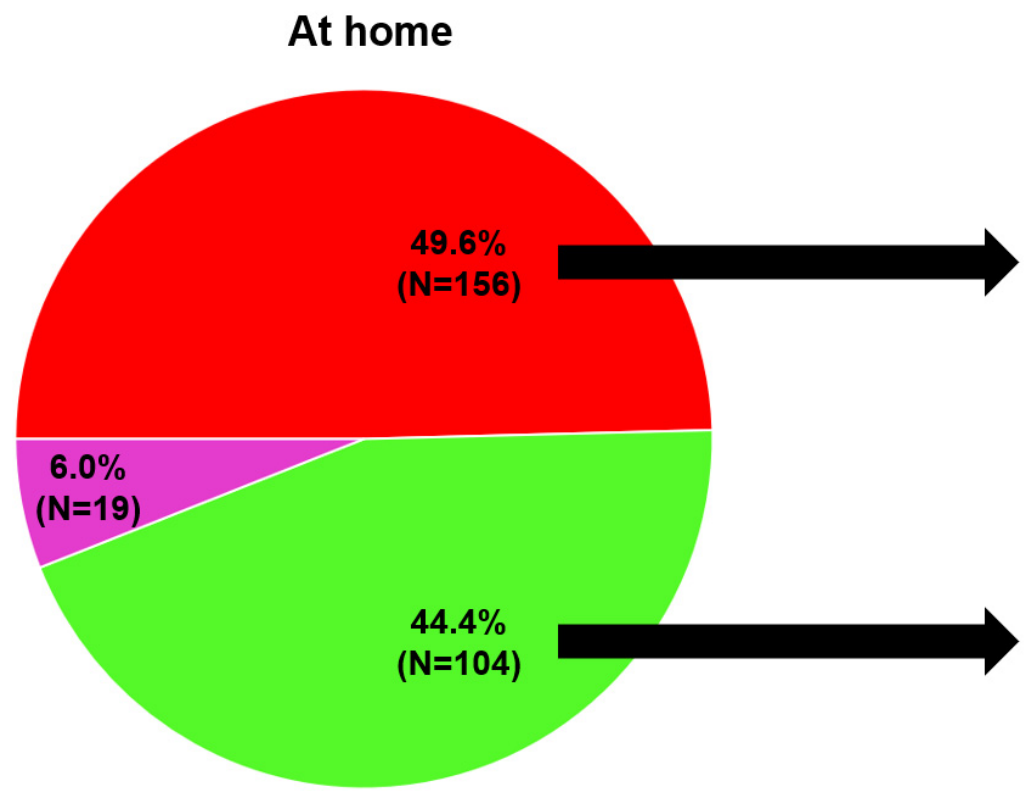

- Job $\backsim$ Student $\square$ Unemployed

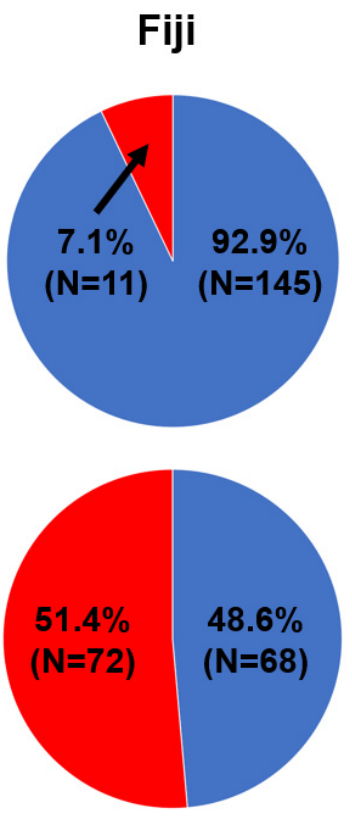

- Holiday - Work

Figure 2. Sample distribution according to occupational status at home and their purpose of visit to Fiji. 
Figure 2 shows that the vast majority of subjects with a job at home came to Fiji for a holiday. For the student groups, about half of the sample came to Fiji for holiday, the other half for work. Most students who reported working in Fiji conducted unpaid work as volunteers, which for the majority comprised building a community health center, teaching, extra-curricular and sports activities with Fijian children while living with a traditional Fijian family. Other students worked in the tourist industry (e.g., work at boats, bars, tour operators, and hotels).

\subsection{Overall Sample}

The demographics of the sample are summarized in Table 1 . The sample was relatively young with both sexes represented $(43.5 \%$ men). There were only few significant differences between subjects who went to Fiji for holiday or work (See Table 1).

Table 1. Demographics for the working and student population.

\begin{tabular}{|c|c|c|c|c|c|c|c|c|}
\hline & \multicolumn{3}{|c|}{ Whole Sample } & \multicolumn{2}{|c|}{ Job at Home } & \multicolumn{3}{|c|}{ Students } \\
\hline & Overall & $\begin{array}{l}\text { In Fiji on } \\
\text { Holiday }\end{array}$ & $\begin{array}{l}\text { In Fiji for } \\
\text { Work }\end{array}$ & $\begin{array}{l}\text { In Fiji on } \\
\text { Holiday }\end{array}$ & $\begin{array}{l}\text { In Fiji for } \\
\text { Work }\end{array}$ & Overall & $\begin{array}{l}\text { In Fiji on } \\
\text { Holiday }\end{array}$ & $\begin{array}{l}\text { In Fiji for } \\
\text { Work }\end{array}$ \\
\hline $\mathrm{N}$ & 333 & 246 & 87 & 145 & 11 & 140 & 68 & 72 \\
\hline $\begin{array}{c}\text { Sex } \\
\text { (Men/Women) }\end{array}$ & $145 / 188$ & $115 / 131$ & $30 / 57^{+}$ & $71 / 74$ & $6 / 5$ & $51 / 89$ & $29 / 39$ & $22 / 50$ \\
\hline Age (years) & $23.5(4.2)$ & $24.5(4.3)$ & $20.9(2.4)^{\dagger}$ & $26.0(4.2)$ & 23.9 (3.3) & $\begin{array}{l}20.9 \\
(2.2)\end{array}$ & $21.4(2.3)$ & $20.4(1.9)^{\dagger}$ \\
\hline $\mathrm{BMI}\left(\mathrm{kg} / \mathrm{m}^{2}\right)$ & $23.5(3.9)$ & $23.6(4.0)$ & $23.1(3.7)$ & $23.8(4.4)$ & $24.5(5.1)$ & $\begin{array}{l}23.0 \\
(3.2)\end{array}$ & $23.1(3.0)$ & 22.9 (3.5) \\
\hline $\begin{array}{c}\text { Alcoholic } \\
\text { drinks / week at } \\
\text { home }\end{array}$ & 11.5 (10.9) & $11.4(11.2)$ & $11.6(10.1)$ & $11.0(11.0)$ & $15.4(12.2)$ & $\begin{array}{c}11.6 \\
(10.6)\end{array}$ & $12.1(11.2)$ & $11.1(10.0)$ \\
\hline $\begin{array}{c}\text { Alcoholic } \\
\text { drinks/day in } \\
\text { Fiji }\end{array}$ & $6.0(5.2)$ & $5.7(5.0)$ & $6.8(5.4)$ & $6.0(5.6)$ & $7.4(6.1)$ & $6.0(4.7)$ & $5.3(3.7)$ & $6.6(5.4)$ \\
\hline $\begin{array}{c}\text { Total sleep } \\
\text { time, h (in Fiji) }\end{array}$ & $6.9(1.4)$ & $7.1(1.3)$ & $6.3(1.5)^{\dagger}$ & $7.2(1.3)$ & $6.6(1.1)$ & $6.5(1.5)$ & $6.8(1.4)$ & $6.3(1.5)^{\dagger}$ \\
\hline $\begin{array}{l}\text { Sleep quality } \\
\text { (in Fiji) }\end{array}$ & $6.4(1.7)$ & $6.6(1.7)$ & $5.9(1.6)^{\dagger}$ & $6.7(1.6)$ & $6.5(1.5)$ & $6.1(1.6)$ & $6.3(1.6)$ & $6.0(1.5)$ \\
\hline Days abroad & 78 (103) & 88 (116) & $52(41)^{\dagger}$ & 79 (114) & $97(93)^{+}$ & $61(72)$ & $78(99)$ & $46(22)$ \\
\hline Days in Fiji & $26(26)$ & $19(25)$ & $44(21)^{\dagger}$ & $20(26)$ & $61(33)^{\dagger}$ & $30(23)$ & $19(24)$ & $41(18)^{\dagger}$ \\
\hline
\end{tabular}

Mean and standard deviation are shown (between brackets). Significant differences $(p<0.05)$ between subjects being in Fiji "on holiday" or "for work" are indicated by ${ }^{\dagger}$.

Subjects in Fiji for a holiday were significantly older $(p<0.0001)$, more often female $(p=0.047)$, and were significantly fewer days abroad than those who came to Fiji for work $(p<0.0001)$, and fewer days in Fiji $(p=0.028)$. Subjects in Fiji for work did not differ from subjects on holiday in alcohol consumption. However, subjects in Fiji for work did report a significant shorter total sleep time of 48 min per night $(p<0.0001)$ and a corresponding significantly poorer sleep quality $(p=0.001)$ compared to subjects on holiday.

Only $\mathrm{N}=11$ of the working sample came to Fiji for work (Group 1), and although they were added to Table 1, it should be noted that the small sample size does not allow reliable statistical comparisons with the subjects who have a job and came to Fiji for a holiday. The small group of subjects who have a job at home and came to Fiji to work is therefore not further considered in this paper. The $\mathrm{N}=19$ subjects that were unemployed at home were not considered in the analyses.

Students in Fiji for work were significantly younger $(p=0.002)$ and stayed significantly more days in Fiji $(p<0.0001)$ than students who came to Fiji for a holiday. Students working in Fiji also reported a significantly shorter total sleep time than students on holiday $(p=0.013)$. Students in Fiji for work did not significantly differ in alcohol consumption (either at home of in Fiji) from students in Fiji for work. 
A summary of assessments of perceived immune fitness and mood is given in Table 2. Analysis revealed that, for the sample as a whole, "in Fiji" ratings showed significant improvements $(p<0.0001)$ for immune fitness $(+14.3 \%)$, stress $(-62.5 \%)$, anxiety $(-57.1 \%)$, depression $(-63.2 \%)$, being active $(-18.2 \%)$, fatigue $(-27.1 \%)$, and anger $(-60.9 \%)$.

Table 2. Immune fitness and mood of the study sample.

\begin{tabular}{cccccccccc}
\hline & \multicolumn{3}{c}{ Overall } & \multicolumn{3}{c}{ In Fiji on Holiday } & \multicolumn{3}{c}{ In Fiji for Work } \\
\cline { 2 - 9 } & Home & Fiji & $\boldsymbol{\Delta}$ & Home & Fiji & $\boldsymbol{\Delta}$ & Home & Fiji & $\boldsymbol{\Delta}$ \\
\hline Immune fitness & $7.0(2.3)$ & $8.0(1.6)^{*}$ & +1.0 & $7.2(2.2)$ & $8.0(1.6)^{*}$ & +0.8 & $6.3(2.4)$ & $7.9(1.5)^{*}$ & $+1.6^{+}$ \\
Stress & $4.8(2.4)$ & $1.8(1.8)^{*}$ & -3.0 & $4.9(2.5)$ & $1.8(1.8)^{*}$ & -3.1 & $4.4(2.1)$ & $1.8(1.6)^{*}$ & -2.6 \\
Anxiety & $3.5(2.7)$ & $1.5(1.9)^{*}$ & -2.0 & $3.5(2.8)$ & $1.5(1.9)^{*}$ & -2.0 & $3.3(2.6)$ & $1.6(1.9)^{*}$ & -1.7 \\
Depression & $1.9(2.4)$ & $0.7(1.5)^{*}$ & -1.2 & $2.0(2.5)$ & $0.7(1.5)^{*}$ & -1.3 & $1.5(1.9)$ & $0.7(1.4)^{*}$ & -0.8 \\
Being active & $6.6(2.4)$ & $5.4(2.8)^{*}$ & -1.2 & $6.6(2.4)$ & $5.2(2.9)^{*}$ & -1.4 & $6.6(2.4)$ & $6.1(2.3)^{\dagger}$ & $-0.5+$ \\
Fatigue & $4.8(2.5)$ & $3.5(2.6)^{*}$ & -1.3 & $4.9(2.6)$ & $3.3(2.5)^{*}$ & -1.6 & $4.6(2.3)$ & $4.3(2.7)^{+}$ & $-0.3+$ \\
Anger & $2.3(2.3)$ & $0.9(1.6)^{*}$ & -1.4 & $2.5(2.5)$ & $1.0(1.7)^{*}$ & -1.5 & $1.7(1.5)^{\dagger}$ & $0.7(1.2)^{*}$ & -1.0 \\
\hline
\end{tabular}

Mean and standard deviation are shown (between brackets). $\Delta$ = change "in Fiji" minus "at home." Significant differences $(p<0.05)$ between "in Fiji" and "at home" are indicated by *. Significant differences $(p<0.05)$ between subjects being in Fiji "on holiday" and "for work" are indicated by ${ }^{\dagger}$.

Subjects in Fiji for work compared to participants in Fiji for a holiday had significantly lower anger scores at home $(p=0.030)$, reported being significantly more active $(p=0.005)$ at home, and had higher fatigue scores in Fiji $(p=0.001)$ compared to subjects that were in Fiji for holiday. Compared to subjects in Fiji for holiday, subjects in Fiji for work reported significantly greater improvements in perceived immune fitness $(+25.4 \%$ versus $+11.1 \%)$, but a significantly smaller reduction in being active $(-7.6 \%$ versus $-21.2 \%)$ and fatigue $(-6.5 \%$ versus $-32.7 \%)$. The subgroup of subjects who were in Fiji for holiday also reported significantly improved ratings $(p<0.0001)$ in Fiji for immune fitness and mood. They also reported being significantly less active in Fiji $(p<0.0001)$. Subjects in Fiji for work also reported significantly improved ratings $(p<0.0001)$ for immune fitness and mood, but no significant difference was reported for being active $(p=0.212)$ and fatigue $(p=0.369)$ relative to the "at home" ratings.

\subsection{The Effect of Having a Holiday in the Working Population}

Subjects who had a job at home were examined separately to investigate the impact of having a holiday on immune fitness and mood. Of the $\mathrm{N}=156$ subjects with a job at home, $\mathrm{N}=145(92.9 \%)$ came to Fiji for a holiday. Types of jobs at home varied greatly across industries, and included positions in administrative/clerical, arts, media, law, service industry, teaching, research, and business. Significant improvement was found on all assessments (See Table 3).

Table 3. Immune fitness and mood among a working sample on holiday in Fiji.

\begin{tabular}{cccc}
\hline & \multicolumn{3}{c}{ Work at Home, on Holiday in Fiji } \\
\cline { 2 - 4 } & Home & Fiji & $\Delta$ \\
\hline Immune fitness & $7.3(2.1)$ & $8.1(1.5)^{*}$ & +0.8 \\
Stress & $5.0(2.6)$ & $1.7(2.0)^{*}$ & -3.3 \\
Anxiety & $3.6(2.8)$ & $1.4(1.8)^{*}$ & -2.2 \\
Depression & $2.1(2.6)$ & $0.6(1.5)^{*}$ & -1.5 \\
Being active & $6.5(2.6)$ & $5.2(2.8)^{*}$ & -1.3 \\
Fatigue & $5.2(2.7)$ & $3.3(2.5)^{*}$ & -1.9 \\
Anger & $2.7(2.6)$ & $0.9(1.6)^{*}$ & -1.8 \\
\hline
\end{tabular}

Mean and standard deviation are shown (between brackets). $\Delta=$ difference "in Fiji" minus "at home." Significant differences $(p<0.05)$ between being "in Fiji" and "at home" are indicated by *. 


\subsection{Work versus Holiday in the Student Population}

About half of the students went to Fiji for holiday and the other half went to Fiji for work. Their data is summarized in Table 4 . For the student sample as a whole, staying in Fiji was associated with significant improvements in ratings for immune fitness and mood. Students in Fiji for holiday reported significantly improved ratings for immune fitness and mood, and they were significantly less active in Fiji. Students in Fiji for work also reported significantly improved ratings $(p<0.0001)$ for immune fitness and mood, although no significant difference was reported for being active $(p=0.121)$ and fatigue $(p=0.312)$.

Table 4. Immune fitness and mood among students.

\begin{tabular}{|c|c|c|c|c|c|c|c|c|c|}
\hline & \multicolumn{3}{|c|}{ Student Sample } & \multicolumn{3}{|c|}{ In Fiji on Holiday } & \multicolumn{3}{|c|}{ In Fiji for Work } \\
\hline & Home & Fiji & $\Delta$ & Home & Fiji & $\Delta$ & Home & Fiji & $\Delta$ \\
\hline Immune fitness & $6.6(2.5)$ & $7.9(1.6) *$ & +1.3 & $7.2(2.5)$ & $7.9(1.7) *$ & +0.7 & $6.1(2.4)$ & $7.8(1.4) *$ & $+1.7^{\dagger}$ \\
\hline Stress & $4.5(2.3)$ & $1.7(1.5)$ * & -2.8 & $4.7(2.5)$ & $1.8(1.5)$ * & -2.9 & $4.4(2.2)$ & $1.6(1.4)$ * & -2.8 \\
\hline Anxiety & $3.3(2.7)$ & $1.5(1.9)$ * & -1.8 & $3.3(3.0)$ & $1.5(1.9)$ * & -1.8 & $3.3(2.5)$ & $1.5(1.8)$ * & -1.8 \\
\hline Depression & $1.7(2.2)$ & $0.7(1.5)$ * & -1.0 & $1.9(2.4)$ & $0.8(1.6)$ * & -1.1 & $1.6(2.0)$ & $0.7(1.4)$ * & -0.9 \\
\hline Being active & $6.7(2.3)$ & $5.5(2.8)$ * & -1.3 & $6.8(2.1)$ & $5.1(3.2) *$ & -1.7 & $6.6(2.4)$ & $6.0(2.4)$ & -0.6 \\
\hline Fatigue & $4.3(2.5)$ & $3.7(2.7)$ * & -0.6 & $4.0(2.5)$ & $3.0(2.6)$ * & -1.0 & $4.7(2.4)$ & $4.3(2.7)^{\dagger}$ & -0.4 \\
\hline Anger & $2.0(2.1)$ & $0.8(1.4)$ * & -1.2 & $2.3(2.5)$ & $1.0(1.7)$ * & -1.3 & $1.7(1.6)$ & $0.7(1.1)$ * & -1.0 \\
\hline
\end{tabular}

Mean and standard deviation are shown (between brackets). $\Delta=$ change "in Fiji" minus "at home." Significant differences $(p<0.05)$ between being "in Fiji" and "at home" are indicated by *. Significant differences $(p<0.05)$ between students who went to Fiji "on holiday" and "for work" are indicated by ${ }^{\dagger}$.

The mood outcomes were comparable between the two groups, although students who worked in Fiji had significantly higher fatigue ratings than those who were in Fiji on holiday $(p=0.004)$. This corresponds to the significant difference in reported sleep hours for the three days before they completed the survey (See Table 1), which was a half hour shorter for working students compared to those on holiday $(p=0.013)$. Interestingly, the observed improvement ("in Fiji" minus "at home") in perceived immune fitness was significantly greater in students in Fiji for work compared to students on holiday in Fiji $(+27.9 \%$ versus $+7.9 \%, p=0.019)$. In conclusion, the strongest reported improvements while being in Fiji for the sample as a whole was observed for stress (-3.0) (See Table 2).

The relative change scores ( $\Delta$, "in Fiji" minus "at home") for immune fitness and mood for the various subgroups in this study are summarized in Figure 3. It shows that the improvement in immune fitness was most prominent in students who went to Fiji for work $(+1.7)$ and smallest in students on holiday $(+0.7)$. Stress reduction was most pronounced in people with a job at home who were having a holiday in Fiji (-3.3). This subsample also reported the greatest positive effects on mood. Students on holiday in Fiji reported the greatest reduction in being active (-1.7).

Finally, Figure 4 shown the percentages of subjects that have reduced immune fitness (scores below 6) for the different populations in Fiji. Significant reductions in percentages of subjects with reduced immune fitness were observed for all subgroups visiting Fiji when compared to at home $(p<0.0001)$. For the population as a whole, the percentage of subjects with reduced immune fitness was $27.6 \%$ at home versus $6.6 \%$ in Fiji. The highest percentage of subjects having reduced immune fitness at home was found among students who came to Fiji for work (40.3\%). This subsample also showed the largest reduction in percentage of subject having reduced immune fitness (Fiji minus home). The lowest percentage of reduced immune fitness in Fiji was found among working subjects on holiday in Fiji (4.9\%). 


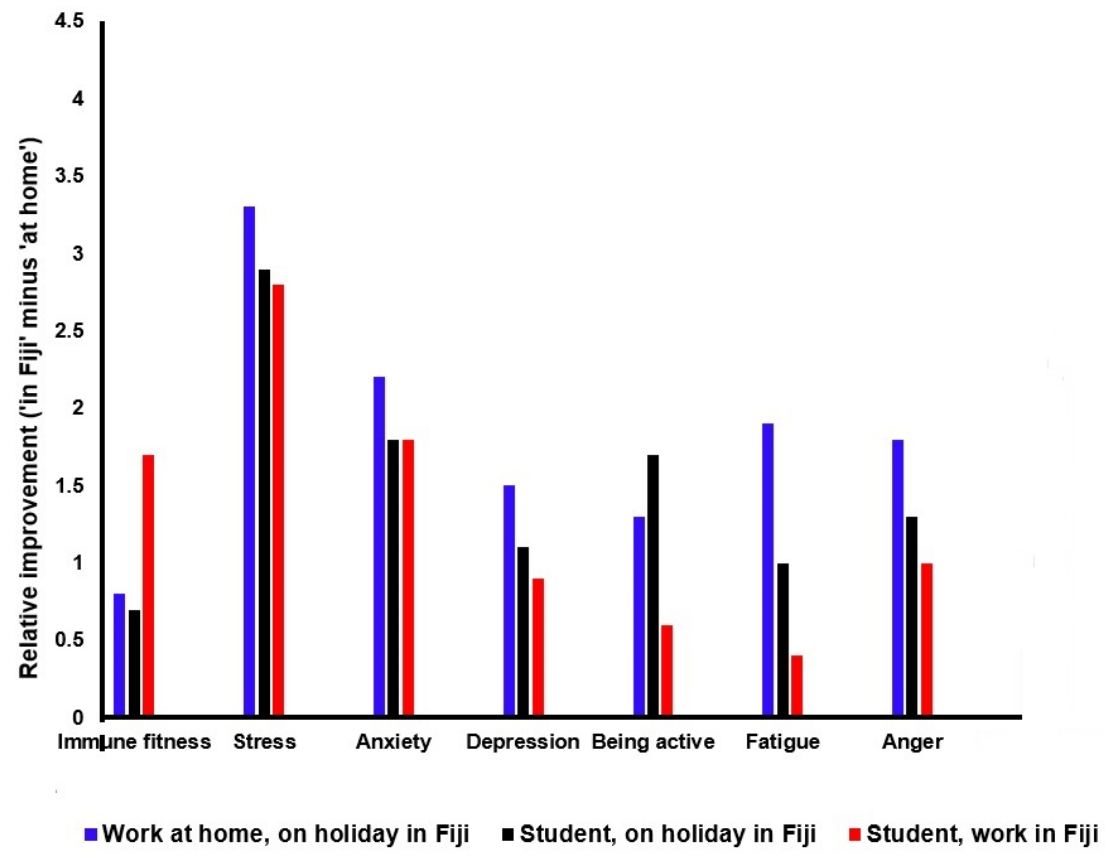

Figure 3. Immune fitness and mood for different populations in Fiji.

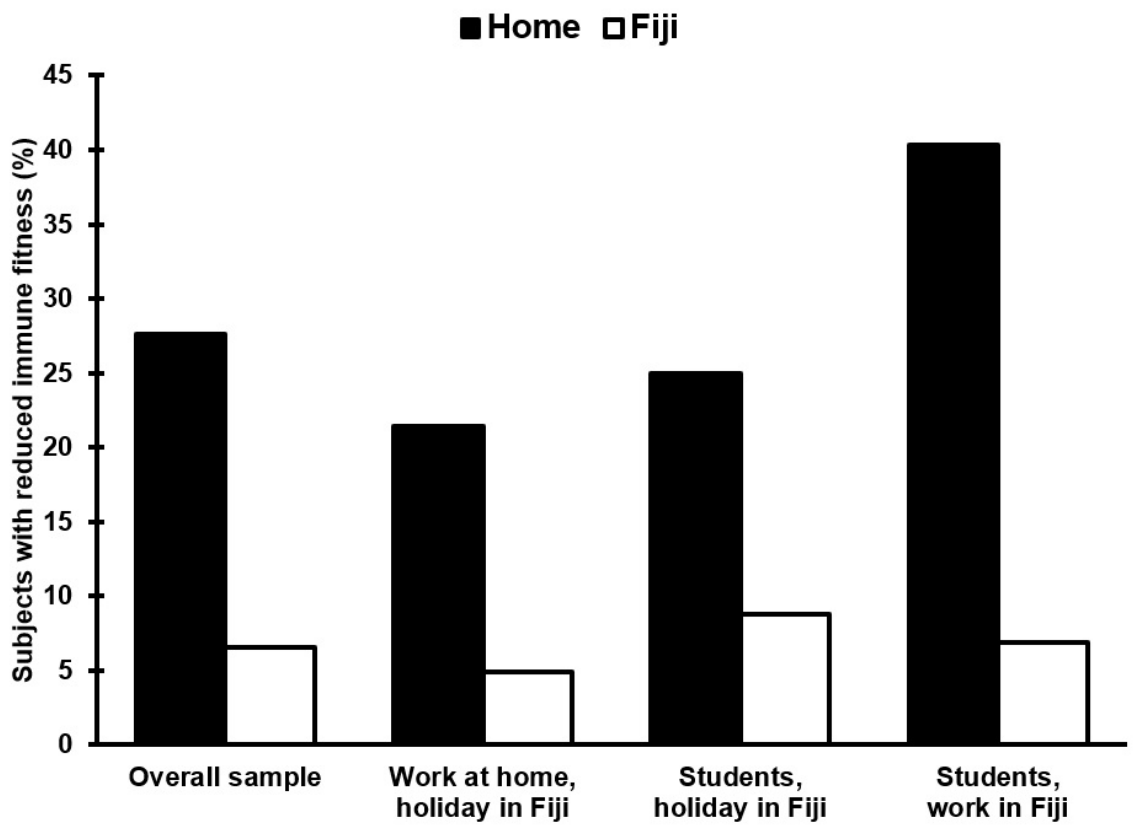

Figure 4. Percentages of reduced immune fitness at home and in Fiji.

\subsection{Sex Differences}

Summarized in Table 5 are the demographics according to sex for the working and student population. For the sample as a whole, women were significantly younger than men $(23.0 \pm 3.8$ versus $24.2 \pm 4.5$ years old, $p=0.027)$ and had a significantly lower body mass index, BMI $\left(22.5 \pm 3.0\right.$ versus $\left.24.7 \pm 4.5 \mathrm{~kg} / \mathrm{m}^{2}, p<0.0001\right)$. No sex differences were found for days abroad or days in Fiji. 
Table 5. Demographics according to sex for the working and student population.

\begin{tabular}{ccccccc}
\hline & \multicolumn{2}{c}{ Work at Home, Holiday in Fiji } & \multicolumn{2}{c}{ Students, Working in Fiji } & \multicolumn{2}{c}{ Students, Holiday in Fiji } \\
\cline { 2 - 6 } & Men & Women & Men & Women & Men & Women \\
\hline N & 71 & 74 & 22 & 50 & 29 & 39 \\
Age (years) & $26.7(4.4)$ & $25.4(3.9)^{\ddagger}$ & $20.9(2.5)$ & $20.2(1.6)$ & $21.0(2.4)$ & $21.7(2.2)^{\dagger}$ \\
BMI (kg/m $\left.{ }^{2}\right)$ & $25.0(5.1)$ & $22.6(3.2)^{\ddagger}$ & $25.0(4.3)$ & $22.0(2.5)$ & $23.4(2.9)$ & $22.9(3.1)$ \\
Alcoholic drinks/week at home & $11.7(9.3)$ & $10.4(12.4)$ & $14.9(13.1)$ & $9.4(7.8)^{\dagger}$ & $13.8(13.6)$ & $10.8(8.7)$ \\
Alcoholic drinks/day in Fiji & $7.5(6.5)$ & $4.5(4.0)^{\ddagger}$ & $10.1(4.4)$ & $5.1(5.1)^{\dagger}$ & $6.8(4.6)$ & $4.1(2.5)^{\dagger}$ \\
Total sleep time in Fiji (h) & $7.3(1.2)$ & $7.1(1.4)$ & $6.4(1.8)$ & $6.2(1.4)$ & $6.9(1.7)$ & $6.8(1.2)$ \\
Sleep quality in Fiji & $6.8(1.6)$ & $6.7(1.6)$ & $6.0(1.5)$ & $6.0(1.6)$ & $6.4(1.9)$ & $6.3(1.4)$ \\
Days abroad & $66.5(103.8)$ & $91.7(123.2)$ & $55.5(22.9)$ & $41.2(19.6)$ & $77.2(105.1)$ & $79.3(95.5)$ \\
Days in Fiji & $22.5(32.0)$ & $17.3(17.9)$ & $48.4(22.3)$ & $37.9(14.3)$ & $20.7(29.0)^{\dagger}$ & $17.9(18.7)^{\dagger}$ \\
\hline
\end{tabular}

Mean and standard deviation are shown (between brackets). Significant differences $(p<0.05)$ between students who went to Fiji "on holiday" and "for work" are indicated by ${ }^{\dagger}$. Significant differences $(p<0.05)$ between men and women are indicated by $\ddagger$.

For the working population, men on holiday were significantly older $(p=0.041)$, had a significantly higher BMI $(p<0.0001)$, and consumed significantly more alcohol on Fiji $(p=0.001)$ compared to working women on holiday. Further, "at home" ratings for stress and anxiety were significantly higher in women than in men $(p=0.001)$.

Male students working in Fiji consumed significantly more alcohol per week at home $(p=0.033)$ and in Fiji $(p<0.0001)$ compared to female students working in Fiji. No significant sex difference in alcohol consumption was seen among students on holiday in Fiji.

Table 6 summarizes the immune fitness and mood ratings of working men and women that were on holiday in Fiji. In working men, significant improvements for "in Fiji" ratings were observed for perceived immune fitness and mood. Similarly, in working women, improvements for "in Fiji" ratings for perceived immune fitness and mood were all statistically significant. Compared to men, in women the magnitude of improvements $(\Delta$, "in Fiji" minus "at home") were significantly greater for $\Delta$ stress $(p<0.0001)$ and $\Delta$ anxiety $(p=0.002)$. Both men and women show improvements towards the same level of mood and immune functioning: in Fiji no significant sex differences were found (See Table 6).

Table 6. Perceived immune fitness and mood of working men and women on holiday in Fiji.

\begin{tabular}{ccccc}
\hline & \multicolumn{2}{c}{ Working Men on Holiday } & \multicolumn{2}{c}{ Working Women on Holiday } \\
\cline { 2 - 5 } & Home & Fiji & Home & Fiji \\
\hline Immune fitness & $7.5(2.1)$ & $8.2(1.5)^{*}$ & $7.2(2.0)$ & $8.0(1.5)^{*}$ \\
Stress & $4.2(2.6)$ & $1.7(1.9)^{*}$ & $5.7(2.4) \ddagger$ & $1.6(2.0)^{*}$ \\
Anxiety & $2.9(2.6)$ & $1.3(1.9)^{*}$ & $4.3(2.8)^{\ddagger}$ & $1.5(1.8)^{*}$ \\
Depression & $1.8(2.5)$ & $0.5(1.6)^{*}$ & $2.4(2.8)$ & $0.7(1.5)^{*}$ \\
Being active & $6.9(2.5)$ & $5.6(2.8)^{*}$ & $6.2(2.7)$ & $4.8(2.8)^{*}$ \\
Fatigue & $4.8(2.7)$ & $3.3(2.5)^{*}$ & $5.5(2.7)$ & $3.2(2.6)^{*}$ \\
Anger & $2.6(2.5)$ & $1.0(1.8)^{*}$ & $2.7(2.7)$ & $0.7(1.5)^{*}$ \\
\hline
\end{tabular}

Mean and standard deviation are shown (between brackets). Significant differences $(p<0.05)$ between "in Fiji" and "at home" are indicated by *. Significant differences $(p<0.05)$ between men and women are indicated by $\neq$.

The student data were also further examined for possible sex differences (See Table 7). Among students on holiday in Fiji, women reported significantly lower (poorer) ratings of immune fitness at home $(p=0.014)$, and significantly more stress $(p=0.008)$ at home than men. In Fiji, female students on holiday reported being significantly less active than men $(p=0.030)$. No significant sex differences in perceived immune functioning or mood were found in students who went to Fiji for work. 
Table 7. Immune fitness and mood among male and female students.

\begin{tabular}{|c|c|c|c|c|c|c|c|c|}
\hline & \multicolumn{4}{|c|}{ Students in Fiji on Holiday } & \multicolumn{4}{|c|}{ Students in Fiji for Work } \\
\hline & \multicolumn{2}{|c|}{ Men } & \multicolumn{2}{|c|}{ Women } & \multicolumn{2}{|c|}{ Men } & \multicolumn{2}{|c|}{ Women } \\
\hline & Home & Fiji & Home & Fiji & Home & Fiji & Home & Fiji \\
\hline Immune fitness & $8.0(1.9)^{\dagger}$ & $7.7(2.0)$ & $6.5(2.6) \ddagger$ & $8.1(1.5) *$ & $6.3(2.4)$ & $7.9(1.5) *$ & $6.0(2.4)$ & $7.8(1.4)$ * \\
\hline Stress & $3.8(2.4)$ & $1.8(1.6) *$ & $5.4(2.3)^{\ddagger}$ & $1.8(1.5) *$ & $4.0(2.2)$ & $1.7(1.2) *$ & $4.5(2.2)$ & $1.5(1.5)$ * \\
\hline Anxiety & $2.4(2.5)$ & $1.5(1.9) *$ & $3.9(3.1)$ & $1.5(1.9)$ * & $3.0(2.5)$ & $1.4(1.9) *$ & $3.5(2.6)$ & $1.6(1.8)$ * \\
\hline Depression & $1.7(2.4)$ & $0.8(1.4) *$ & $2.0(2.5)$ & $0.7(1.7) *$ & $1.9(2.0)$ & $1.0(2.0) *$ & $1.5(2.0)$ & $0.5(1.0)$ * \\
\hline Being active & $7.1(2.4)$ & $6.0(3.0)$ & $6.6(1.8)$ & $4.4(3.2) * \dagger \ddagger$ & $6.5(2.3)$ & $6.1(2.1)$ & $6.7(2.5)$ & $5.9(2.5)$ \\
\hline Fatigue & $4.2(2.5)$ & $3.7(2.6)$ & $3.8(2.6)$ & $2.6(2.5) *+$ & $4.4(2.2)$ & $4.0(2.7)$ & $4.8(2.5)$ & $4.5(2.7)$ \\
\hline Anger & $2.4(2.9)$ & $1.3(2.1)$ * & $2.1(2.3)$ & $0.8(1.2)$ & $2.1(1.6)$ & $0.7(1.1)^{*}$ & $1.6(1.5)$ & $0.6(1.1)^{*}$ \\
\hline
\end{tabular}

Mean and standard deviation are shown (between brackets). Significant differences $(p<0.05)$ between "in Fiji" and "at home" are indicated by *. Significant differences $(p<0.05)$ between students who went to Fiji "on holiday" and "for work" are indicated by ${ }^{\dagger}$. Significant differences $(p<0.05)$ between men and women are indicated with $¥$.

The overall results of the analysis of sex differences for the various subgroups of the sample are summarized in Figure 5. It is evident from Figure 5 that female students on holiday experienced the greatest improvements in perceived immune fitness. Working women on holiday experienced the greatest improvements in mood.

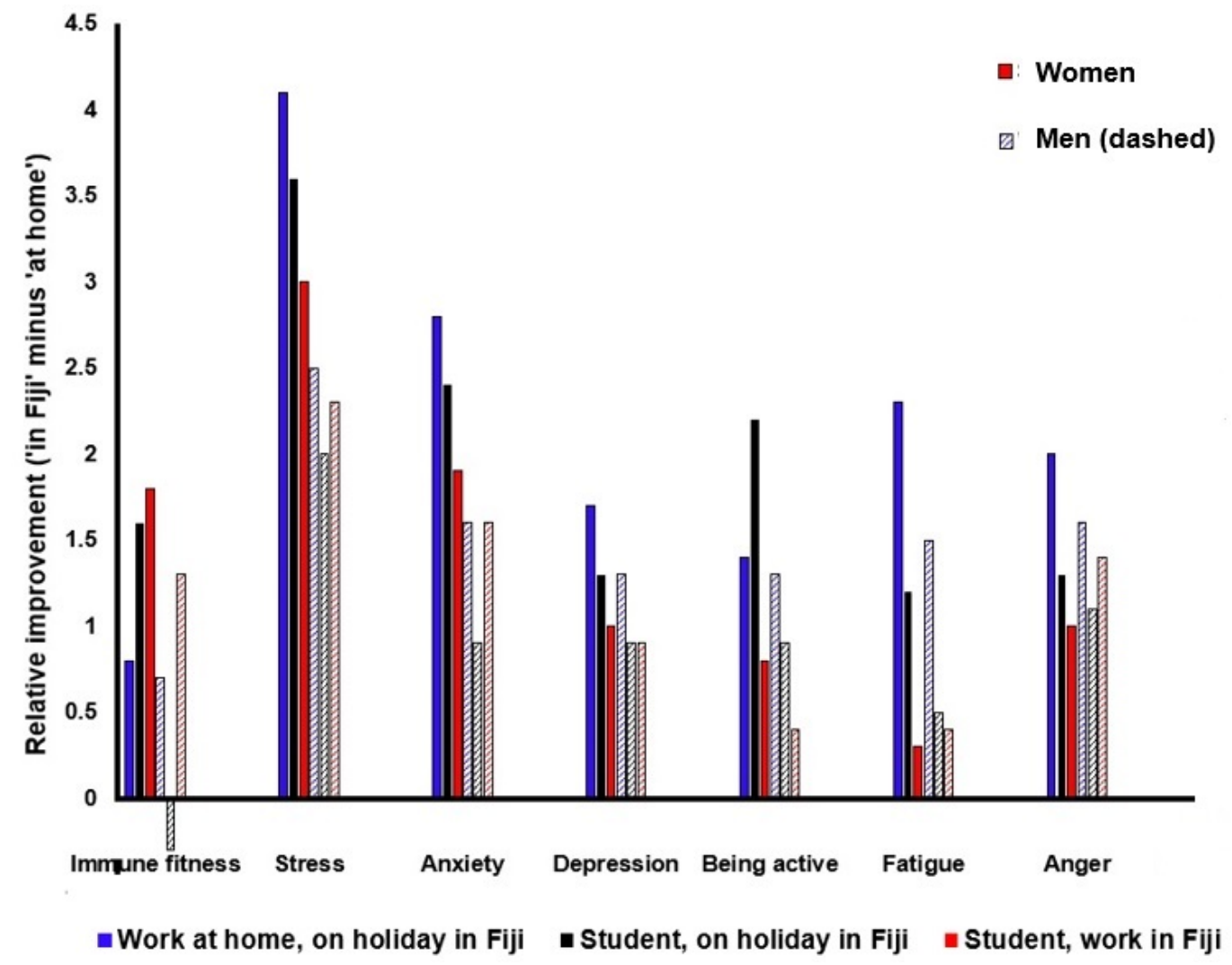

Figure 5. Sex differences in immune fitness and mood.

\subsection{Levels of Mood and Immune Fitness at Home (before Traveling)}

Correlations between difference scores ( $\Delta=$ "in Fiji" minus "at home") were calculated for immune fitness and mood ratings. These were correlated with the same ratings made at home. Correlations for the sample as a whole are depicted in Figure 6, and correlations for the subsamples are listed in Table 8 . All correlations were statistically significant at the $p<0.0001$ level, except for being active for students on holiday in Fiji $(p=0.028)$. 

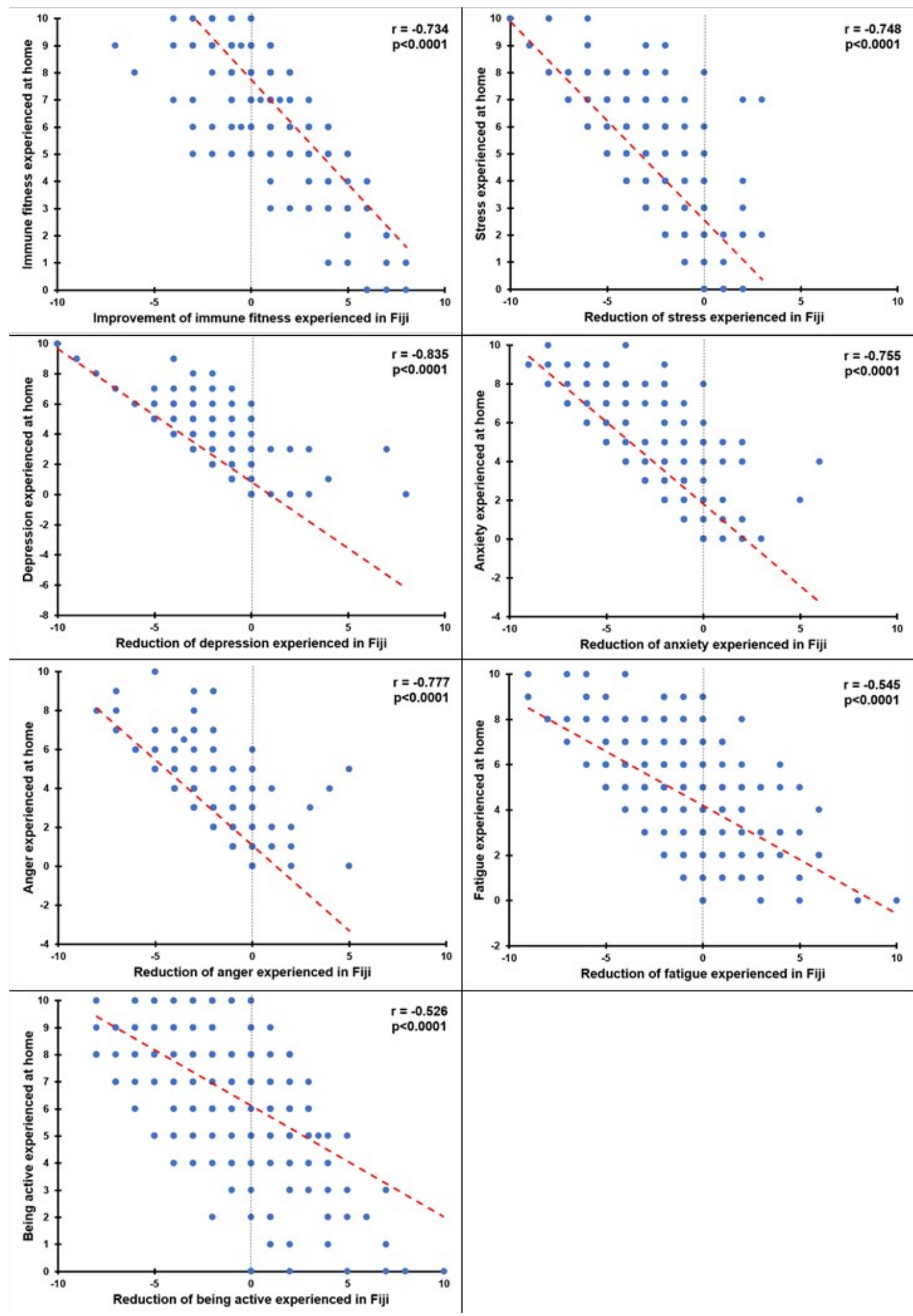

Figure 6. Impact of "at home" ratings on perceived immune fitness and mood in Fiji. Bivariate correlations between "at home" ratings and changes of perceived immune fitness and mood (change score = "at home" minus "in Fiji") are presented. Negative scores on the X-axis present an improvement in the rating relative to "at home." Higher scores "at home" are associated with greater reductions "in Fiji." Red lines represent Spearman's rho correlations. All correlations were statistically significant $(p<0.0001)$. 
Table 8. Correlations between at home mood ratings and $\Delta$ immune fitness and mood.

\begin{tabular}{cccccccc}
\hline & \multicolumn{3}{c}{ Whole Sample } & Work at Home & \multicolumn{2}{c}{ Students } \\
\cline { 2 - 7 } & Overall & $\begin{array}{c}\text { In Fiji on } \\
\text { Holiday }\end{array}$ & $\begin{array}{c}\text { In Fiji for } \\
\text { Work }\end{array}$ & $\begin{array}{c}\text { In Fiji on } \\
\text { Holiday }\end{array}$ & Overall & $\begin{array}{c}\text { In Fiji on } \\
\text { Holiday }\end{array}$ & $\begin{array}{c}\text { In Fiji for } \\
\text { Work }\end{array}$ \\
\hline Immune fitness & -0.734 & -0.703 & -0.797 & -0.675 & -0.797 & -0.762 & -0.830 \\
Stress & -0.748 & -0.747 & -0.727 & -0.725 & -0.803 & -0.807 & -0.798 \\
Depression & -0.835 & -0.837 & -0.827 & -0.872 & -0.863 & -0.847 & -0.870 \\
Anxiety & -0.755 & -0.763 & -0.737 & -0.783 & -0.762 & -0.777 & -0.725 \\
Fatigue & -0.545 & -0.562 & -0.489 & -0.557 & -0.506 & -0.544 & -0.514 \\
Being active & -0.526 & -0.459 & -0.701 & -0.518 & -0.486 & -0.267 & -0.663 \\
Anger & -0.777 & -0.779 & -0.784 & -0.824 & -0.805 & -0.785 & -0.831 \\
\hline
\end{tabular}

All correlations were statistically significant at the $p<0.0001$ level, except for being active for students on holiday in Fiji $(p=0.028)$.

The data show that the observed improvements significantly depend on the ratings of mood and immune fitness that were experienced before traveling. That is, the poorer the at home ratings of mood and immune fitness, the more improvement was observed from staying in Fiji. The high and significant correlations were seen across all subsamples.

\subsection{Confounding Lifestyle Factors: Alcohol Use and Sleep in Fiji}

For the sample as a whole, no significant correlations were found between changes $(\Delta=$ "in Fiji" minus "at home") in immune fitness and alcohol consumption, total sleep time and quality. However, total sleep time was significantly correlated with $\Delta$ depression $(\mathrm{r}=-0.112, p=0.044)$ and $\Delta$ fatigue $(\mathrm{r}=-0.297, p<0.0001)$. Sleep quality was also significantly associated with $\Delta$ fatigue $(\mathrm{r}=-0.156, p=0.005)$ and alcohol consumption in Fiji was positively associated with $\Delta$ being active $(\mathrm{r}=0.114, p=0.039)$. In men, sleep quality was significantly and negatively associated with $\Delta$ fatigue $(\mathrm{r}=-0.262, p=0.002)$, whereas sleep quality correlated significantly and positively with $\Delta$ anger $(r=0.213, p=0.010)$. Alcohol consumption was positively associated with $\Delta$ being active $(\mathrm{r}=0.167, p=0.045)$, and negatively with $\Delta$ anger $(\mathrm{r}=-0.166, p=0.047)$. In women, total sleep time was significantly associated with $\Delta$ anxiety $(\mathrm{r}=-0.163, p=0.029)$ and $\Delta$ fatigue $(\mathrm{r}=-0.336$, $p<0.0001)$, sleep quality correlated significantly with $\Delta$ fatigue $(\mathrm{r}=-0.194, p=0.009)$, and alcohol consumption correlated significantly with $\Delta$ anger $(r=0.153, p=0.037)$.

\subsection{Days Traveling and in Fiji}

It was further investigated whether the time abroad and days of traveling had an impact on the observed associations. The significant correlation between $\Delta$ immune fitness and $\Delta$ stress did not substantially alter when adjusting for the number of days abroad $(\mathrm{r}=0.127, p=0.021)$ or the number of days in Fiji $(\mathrm{r}=0.147, p=0.008)$. The improvement in reported immune fitness correlated significantly with the number of days being in Fiji $(\mathrm{r}=0.142, p=0.010)$, but not significantly with the total number of days abroad $(\mathrm{r}=0.041$, $p=0.456)$. Similarly, the improvement in reported stress correlated significantly with the number of days being in Fiji $(\mathrm{r}=-0.209, p<0.0001)$, but not significantly with the total number of days abroad $(\mathrm{r}=-0.072, p=0.189)$. Improvements in other mood outcomes did not significantly correlate with either the number of days abroad or the duration of their stay in Fiji.

\section{Discussion}

The current study suggests that having a holiday in Fiji is associated with significantly improved perceived immune fitness $(+14.3 \%)$ and significantly reduced stress $(-62.5 \%)$. These observations were accompanied by significantly improved other mood ratings while in Fiji. The improvements were seen both in a working population and a student sample in Fiji for a holiday. Having a holiday or working in Fiji significantly improved immune fitness and mood. The reported improvements in immune fitness were most pronounced for female students on holiday in Fiji $(+27.9 \%)$, whereas the improvements in mood were 
largest among working women on holiday in Fiji. Students who came to Fiji for work reported significantly higher levels of fatigue than students and people with a job at home that were on holiday in Fiji. They were also more active than holidaymakers. The improvements observed in perceived immune fitness and stress were significantly associated with the number of days being in Fiji. Interestingly, the improvements were not significantly associated with the total number of days being abroad, suggesting that specific environmental characteristics of Fiji may have contributed to the reported improvements. Further research should investigate these currently unknown social, cultural, and environment factors that make Fiji different from other countries in terms of generating positive health effects. A direct comparison with other holiday destinations is therefore warranted. It is important to rule out a possible impact of socioeconomic inequalities [21], because it may depend on socioeconomic status and country of origin if one can afford having a holiday in Fiji.

Our research is in line with previous research in that the study confirms that having a holiday has positive effects on mood. For example, a meta-analysis by De Bloom et al. [22] found that having a vacation had positive effects on health and well-being. A recent study revealed that a 4-day holiday in German middle managers had significant positive effects on perceived stress, recovery, strain, and well-being [23]. Research in adolescents showed that self-reported ratings on depression, anxiety, and everyday hassles were significantly reduced during vacation periods compared to school periods [24]. These examples illustrate the positive effects of having a holiday that were confirmed by our study.

The assessment of perceived immune fitness is critical for several reasons. For example, individuals may feel healthy while they have a medical condition (e.g., people with high blood pressure). Alternatively, individuals may suffer from a condition while no objective trauma or change in biomarkers can be demonstrated (e.g., chronic pain). Notwithstanding this, people often do judge their health status based on their perceived immune status (e.g., feelings of reduced resistance), and based upon their perceived immune fitness they may decide whether or not they make demands on healthcare (e.g., visit a physician) of report being sick and not go to work [18]. Our findings demonstrated that the assessment of perceived immune fitness has added value to assessing mood only. For example, the positive effects on mood were more pronounced in women than men; however, ratings of perceived immune fitness were improved to comparable levels in both sexes. Whereas alcohol consumption and sleep outcomes had a significant impact on reported mood, no significant associations were found between these confounders and perceived immune fitness. Mood changes were independent from the time spent in Fiji. In contrast, the improvement in perceived immune fitness correlated significantly with the number of days being in Fiji. The latter is an important new observation that deserves more research attention. If the duration of a holiday clearly impacts improvements on perceived immune fitness, this may have implications for demands on healthcare and absenteeism for the remaining part of the year, when at home.

Previous research has shown that a sole change of environment (country, temperature) already can have a positive effect on immune fitness and mood. For example, Knez et al. [25] reported that gas field workers who changed from working in a cold environment to working in a hot environment led to a decrease in energy expenditure of $14.8 \%$. However, no significant difference was observed in work performance and output between working in the two countries. The absence of any change in blood leucocyte, monocyte, and lymphocyte counts suggests that an environmental change from a cold to a hot climate country, while continuing to perform the same job, is not accompanied by immunological changes. Studies investigating the effects of sunshine exposure while having a holiday in sunny countries on immune biomarkers are sparse, have small sample sizes, and show mixed results regarding immune-suppressant or immune-stimulating effects [26-30]. For example, Falkenbach and Sedlmeyer [30] demonstrated that traveling to sunny countries is accompanied by immunological changes, suggesting a poorer immune functioning after traveling. The effects were more pronounced in subjects having a long 
versus a short holiday, and the authors suggest that increased exposure to sunshine, i.e., ultraviolet light, is the main cause of the observed immunological changes. However, various factors other than mere exposure to increased sunshine may account for the observed differences in immunological responses, and future research should investigate these. Perceived immune fitness and mood accompanying the observed objective immunological changes were not assessed in studies addressing sunshine effects on immune functioning. Future studies should implement subjective assessments of perceived immune fitness in their design. Finally, environmental psychology learns that there are various socioeconomic and cultural factors influencing the relations between humans and their surroundings [31]. These factors were not investigated in the current research but could be taken into account in future research.

In the current study, several sex differences were observed. For example, the female working sample that was in Fiji for holiday reported significantly higher levels of stress and anxiety at home compared to the male working population. The improvement while on holiday in Fiji was significantly greater in women for stress and neuroticism. The observations are in line with previous findings that women often report experiencing higher levels of (job-)stress and mood complaints compared to men.

Up to now, possible sex differences in health benefits of having a holiday are hardly investigated. Kim et al. [32] examined the impact of having paid holidays on the US economy. Data from a nationally-representative US sample of working men and women, 33-41 years old, was interrogated. They found that for every ten days of paid holiday per year, the chances of developing depression in women reduced by $29 \%$, corresponding to an annual cost savings of US $\$ 2.94$ billion on avoided yearly new depression cases. The association between paid vacation days and depression was not significant in men. Albeit the absolute scores for depression were relatively low compared to ratings of stress, the current study showed a significant reduction in depression scores in both men and women. The reduction was most prominent among working women on holiday in Fiji.

One could expect that having a holiday has a fixed effect on perceived immune fitness and mood (e.g., an improvement of 2 points on a scale ranging from 0 to 10 across all subjects). This was, however, not the case. Instead, the data show that the observed improvements significantly depend on the ratings of stress, mood, and immune fitness that were experienced before traveling. That is, subjects with poorer "at home" ratings of mood and immune fitness reported much more benefit from staying in Fiji than subjects with better "at home" ratings of mood and immune fitness. The correlations between improvements in mood and immune fitness were very robust, and their magnitude suggests that having a holiday may pay off in reducing chances of high stress and poor mood developing towards pathological levels. The latter has a relevant economic impact, as illustrated by Kim et al. [32]. Having a holiday may also be a good alternative for various forms of therapy to reduce stress and improve mood in non-clinical samples. Future research should investigate this. For example, a direct comparison could be made between a group of people having a mindfulness course or practicing yoga, and another group having a holiday.

\section{Limitations of the Study and Recommendations for Future Research}

There are several limitations of the current study that should be addressed. First, the sample size was relatively small. As a result, the subsample of subjects both working at home and in Fiji was too small $(\mathrm{N}=11)$ to conduct reliable statistical analysis and comparisons with subjects with a job at home who went to Fiji for a holiday. Future studies should compare these two groups. As an alternative, we compared a sample of subjects who came to Fiji either for work or holiday. When interpreting this data, it should be taken into account that being a student or having a regular job may imply having very different lifestyles at home. It should also be noted that most students who came to Fiji for work were volunteers in a project building a community health center and being engaged in extracurricular and sports activities of Fijian children. It can be debated to what extent unpaid 
volunteer work can be compared to having a regular paid job. For example, volunteering work is often conducted to do "something good" for society in a friendly environment with people with the same mind set. Therefore, volunteering may be a very rewarding and positive experience. In contrast, having a regular job (at home or in Fiji) is usually a necessity to obtain money for living expenses. In contrast to volunteer work, a regular job can imply a highly competitive, unrewarding, and stressful working environment.

Second, the results obtained from this young adult sample cannot be simply extrapolated to older adult populations. Various factors that may have influenced immune fitness and mood were omitted from the current study. For example, dietary changes, the presence or absence of stressors (e.g., crime, violence) and hours of sunshine exposure were not assessed. Also, socioeconomic status and cultural differences between countries of origin were not taken into account. Future studies should thoroughly examine potential confounders of their impact on the effect of having a holiday or a geographical change in working environment on immune fitness, neuroticism, and mood.

Third, the study did not include a control group of subjects who stayed in their home country over the same period of time. Including a control group could rule out (unexpected) seasonal effects on immune fitness and mood. Including such a control group could also be used to examine differences between having a holiday at home versus having a holiday abroad. With a larger sample size it would also be possible to investigate whether or not living location has an impact on the study outcome. The latter is important, as it can be imagined that subjects living in more Northern countries, i.e., a colder climate with less hours of (intensive) sunshine, may benefit more from a change to a warmer climate that subjects who already live in countries with a milder climate.

Fourth, the sample consisted of relatively young participants, aged 18 to 35 years old. An early career working population may differ in terms of mental resilience and experiencing stress and other work-related mood effects than a more senior working population. They may have adopted less effective coping strategies than people with more experience in working settings. This study should be replicated in an older working population to determine to what extent our observations can be generalized to the general working population.

Fifth, the ratings of at-home measures were performed retrospectively while the Fiji measures were performed in situ, making the latter more reliable. It is possible that some of the Fiji-home differences were due to more general perceptions about the psychological benefits of holidaying. As there was a time lag between experiencing mood at home and reporting, recall bias may have influenced the study results. Future prospective studies should be conducted to verify our findings and prevent a possible impact of recall bias.

Sixth, it cannot be concluded from our study that Fiji is a holiday destination with unique specific properties. To demonstrate whether this is the case, studies are needed that directly compare Fiji to other holiday destinations (e.g., beach destination in another country or at home). The location of the current study clearly contributed to the positive mood ratings of participants. It cannot be ruled out that the same results would have been found at other holiday destinations.

Finally, due to logistical difficulties in collecting and storing saliva and blood samples, the current study did not include biomarker assessments. Future studies should aim to include these to objectively verify the reported changes in immune fitness.

\section{Conclusions}

Having a holiday or working in Fiji is associated with significantly improved immune fitness and mood. The reported improvements in immune fitness were most pronounced for female students on holiday in Fiji, whereas the improvements in mood were largest among working women on holiday in Fiji. The magnitude of improvement of immune fitness and reduction in stress was significantly associated with the duration of being in Fiji. The tourism and hospitality industry could embrace and employ these findings as they demonstrate that, in addition to leisure, the outcomes of this study support the notion 
that having a holiday is also beneficial to mental health and perceived immune fitness of both students and the working population.

Author Contributions: Conceptualization, L.A., A.J.A.E.v.d.L., A.S. and J.C.V.; methodology, L.A. and J.C.V.; formal analysis, J.C.V.; investigation, L.A.; writing-original draft preparation, L.A. and J.C.V.; writing-review and editing, all authors. All authors have read and agreed to the published version of the manuscript.

Funding: This research received no external funding.

Institutional Review Board Statement: The study was conducted according to the guidelines of the Declaration of Helsinki, and approved by the Ethics Committee of the Faculty of Social and Behavioral Sciences of Utrecht University (approval code FETC17-061).

Informed Consent Statement: Informed consent was obtained from all subjects involved in the study.

Data Availability Statement: The data presented in this study are available on reasonable request from the corresponding author.

Conflicts of Interest: A.D.K. has received grants/research support from Top Institute Pharma, NWO, Janssen, GSK, Nutricia Research, and Friesland Campina. A.S. has held research grants from Abbott Nutrition, Arla Foods, Bayer Healthcare, Cognis, Cyvex, GlaxoSmithKline, Naturex, Nestle, Martek, Masterfoods, Wrigley, and has acted as a consultant/expert advisor to Abbott Nutrition, Barilla, Bayer Healthcare, Danone, Flordis, GlaxoSmithKline Healthcare, Masterfoods, Martek, Novartis, Unilever, and Wrigley. J.G. is part-time employee of Nutricia Research and received research grants from Nutricia research foundation, Top Institute Pharma, Top Institute Food and Nutrition, GSK, STW, NWO, Friesland Campina, CCC, Raak-Pro, and EU. Over the past 3 years, J.C.V. has received grants/research support from Janssen Research and Development and Sequential Medicine, and has acted as a consultant/advisor for More Labs, Red Bull, Sen-Jam Pharmaceutical, Toast!, Tomo, and ZBiotics. The other authors declare no conflicts of interest.

\section{References}

1. Van der Wal, R.A.; Bucx, M.J.; Hendriks, J.C.; Scheffer, G.J.; Prins, J.B. Psychological distress, burnout and personality traits in Dutch anaesthesiologists: A survey. Eur. J. Anaesthesiol. 2016, 33, 179-186. [CrossRef]

2. Bianchi, R. Burnout is more strongly linked to neuroticism than to work-contextualized factors. Psychiatry Res. 2018, 270, 901-905. [CrossRef]

3. Golonka, K.; Mojsa-Kaja, J.; Blukacz, M.; Gawłowska, M.; Marek, T. Occupational burnout and its overlapping effect with depression and anxiety. Int. J. Occup. Med. Environ. Health 2019, 32, 229-244. [CrossRef] [PubMed]

4. Leiter, M.P.; Maslach, C. Areas of worklife: A structured approach to organizational predictors of job burnout. In Research in Occupational Stress and Well-Being; Perrewe, P.L., Ganster, D.C., Eds.; Elsevier: Oxford, UK, 2004; pp. 91-134.

5. World Health Organization. PRIMA-EF: Guidance on the European Framework for Psychosocial Risk Management: A Resource for Employers and Worker Representatives; World Health Organization: Geneva, Switzerland, 2008. Available online: https: //www.who.int/occupational_health/publications/PRIMA-EF\%20Guidance_9.pdf (accessed on 24 December 2020).

6. European Foundation for the Improvement of Living and Working Conditions. Fourth European Working Conditions Survey. Office for Official Publications of the European Communities: Luxembourg, 2007. Available online: http:/ / www.eurofound. europa.eu/ewco/surveys/index.htm (accessed on 24 December 2020).

7. Schakel, L.; Veldhuijzen, D.S.; Crompvoets, P.I.; Bosch, J.A.; Cohen, S.; van Middendorp, H.; Joosten, S.A.; Ottenhoff, T.H.M.; Visser, L.G.; Evers, A.W.M. Effectiveness of stress-reducing interventions on the response to challenges to the immune system: A meta-analytic review. Psychother. Psychosom. 2019, 88, 274-286. [CrossRef] [PubMed]

8. Strauss-Blasche, G.; Reithofer, B.; Schobersberger, W.; Ekmekcioglu, C.; Marktl, W. Effect of vacation on health: Moderating factors of vacation outcome. J. Travel Med. 2005, 12, 94-101. [CrossRef] [PubMed]

9. Koh, K.B.; Lee, Y.J.; Beyn, K.M.; Chu, S.H.; Kim, D.M.; Seo, W.Y. Effects of high and low stress on proinflammatory and antiinflammatory cytokines. Psychophysiology 2012, 49, 1290-1297. [CrossRef]

10. De Bloom, J.; Radstaak, M.; Geurts, S. Vacation effects on behaviour, cognition and emotions of compulsive and non-compulsive workers: Do obsessive workers go 'cold turkey'? Stress Health 2014, 30, 232-243. [CrossRef]

11. Epel, E.S.; Puterman, E.; Lin, J.; Blackburn, E.H.; Lum, P.Y.; Beckmann, N.D.; Zhu, J.; Lee, E.; Gilbert, A.; Rissman, R.A.; et al. Meditation and vacation effects have an impact on disease-associated molecular phenotypes. Transl. Psychiatry 2016, 6, e880. [CrossRef]

12. Lee, H.W.; Yoo, J.; Cha, J.Y.; Ji, C.H.; Eun, D.; Jang, J.H.; Ju, H.W.; Park, J.M.; Jee, Y.S. Effects of winter skiing on stress, heart rate, apprehension, and enjoyment in collegiate students: A single randomized controlled trial. J. Exerc. Rehabil. 2019, 15, 235-241. [CrossRef] 
13. Ceballos, N.A.; Sharma, S.; Patterson, T.L.; Graham, R.; Howard, K. Stress, immune function and collegiate holiday drinking: A pilot study. Neuropsychobiology 2015, 72, 8-15. [CrossRef]

14. Bellis, M.A.; Hughes, K.E.; Dillon, P.; Copeland, J.; Gates, P. Effects of backpacking holidays in Australia on alcohol, tobacco and drug use of UK residents. BMC Public Health 2007, 7, 1. [CrossRef] [PubMed]

15. Hughes, K.; Bellis, M.A.; Calafat, A.; Blay, N.; Kokkevi, A.; Boyiadji, G.; Mendes Mdo, R.; Bajcàrova, L. Substance use, violence, and unintentional injury in young holidaymakers visiting Mediterranean destinations. J. Travel Med. 2011, 18, 80-89. [CrossRef] [PubMed]

16. Calafat, A.; Bellis, M.A.; Fernández Del Rio, E.; Juan, M.; Hughes, K.; Morleo, M.; Becoña, E.; Duch, M.; Stamos, A.; Mendes, F. Nightlife, verbal and physical violence among young European holidaymakers: What are the triggers? Public Health 2013, 127, 908-915. [CrossRef] [PubMed]

17. Wilod Versprille, L.J.F.; van de Loo, A.J.A.E.; Mackus, M.; Arnoldy, L.; Sulzer, T.A.L.; Vermeulen, S.A.; Abdulahad, S.; Huls, H.; Baars, T.; Scholey, A.; et al. Development and validation of the Immune Status Questionnaire (ISQ). Int. J. Environ. Res. Public Health 2019, 16, 4743. [CrossRef] [PubMed]

18. Donners, A.A.M.T.; Tromp, M.D.P.; Garssen, J.; Roth, T.; Verster, J.C. Perceived immune status and sleep: A survey among Dutch students. Sleep Disord. 2015, 2015, 721607. [CrossRef] [PubMed]

19. Van Schrojenstein Lantman, M.; Otten, L.S.; Mackus, M.; de Kruijff, D.; van de Loo, A.J.A.E.; Kraneveld, A.D.; Garssen, J.; Verster, J.C. Mental resilience, perceived immune functioning, and health. J. Multidiscipl. Healthc. 2017, 10, 107-112. [CrossRef] [PubMed]

20. McNair, D.M.; Lorr, M.; Droppleman, L.F. Manual for the Profile of Mood States; Educational and Industrial Testing Services: San Diego, CA, USA, 1971; pp. 3-29.

21. Morgan, K.; Melendez-Torres, G.J.; Bond, A.; Hawkins, J.; Hewitt, G.; Murphy, S.; Moore, G. Socio-economic inequalities in adolescent summer holiday experiences, and mental wellbeing on return to school: Analysis of the school health research network/health behaviour in school-aged children survey in Wales. Int. J. Environ. Res. Public Health 2019, 16, 1107. [CrossRef] [PubMed]

22. De Bloom, J.; Kompier, M.; Geurts, S.; de Weerth, C.; Taris, T.; Sonnentag, S. Do we recover from vacation? Meta-analysis of vacation effects on health and well-being. J. Occup. Health 2009, 51, 13-25. [CrossRef] [PubMed]

23. Blank, C.; Gatterer, K.; Leichtfried, V.; Pollhammer, D.; Mair-Raggautz, M.; Duschek, S.; Humpeler, E.; Schobersberger, W. Short vacation improves stress-level and well-being in German-speaking middle-managers-A randomized controlled trial. Int. J. Environ. Res. Public Health 2018, 15, 130. [CrossRef] [PubMed]

24. Verma, S.; Allen, N.B.; Trinder, J.; Bei, B. Highs and lows: Naturalistic changes in mood and everyday hassles over school and vacation periods in adolescents. J. Adolesc. 2017, 61, 17-21. [CrossRef]

25. Knez, W.; Girard, O.; Racinais, S.; Walsh, A.; Gaoua, N.; Grantham, J. Does living and working in a hot environment induce clinically relevant changes in immune function and voluntary force production capacity? Ind. Health 2014, 52, 235-239. [CrossRef]

26. Hersey, P.; Haran, G.; Hasic, E.; Edwards, A. Alteration of T cell subsets and induction of suppressor T cell activity in normal subjects after exposure to sunlight. J. Immunol. 1983, 131, 171-174. [PubMed]

27. Bech-Thomsen, N.; Munch-Petersen, B.; Lundgren, K.; Poulsen, T.; Wulf, H.C. UV-induced alterations in skin and lymphocytes during a one-week holiday in the Canary Islands in May. Acta Derm. Venereol. 1993, 73, $422-425$.

28. Viac, J.; Goujon, C.; Misery, L.; Staniek, V.; Faure, M.; Schmitt, D.; Claudy, A. Effect of UVB 311 nm irradiation on normal human skin. Photodermatol. Photoimmunol. Photomed. 1997, 13, 103-108. [CrossRef] [PubMed]

29. Kanariou, M.; Petridou, E.; Vrachnou, E.; Trichopoulos, D. Lymphocyte alterations after prolonged sunlight exposure. J. Epidemiol. Biostat. 2001, 6, 463-465. [CrossRef]

30. Falkenbach, A.; Sedlmeyer, A. Travel to sunny countries is associated with changes in immunological parameters. Photodermatol. Photoimmunol. Photomed. 1997, 13, 139-142. [CrossRef] [PubMed]

31. Nasar, J.L. Advances in environmental psychology. Behav. Sci. 2015, 5, 384-387. [CrossRef]

32. Kim, D. Does paid vacation leave protect against depression among working Americans? A national longitudinal fixed effects analysis. Scand. J. Work Environ. Health 2019, 45, 22-32. [CrossRef] [PubMed] 